\title{
Application of emulsified acids on sandstone formation at elevated temperature conditions: an experimental study
}

\author{
Mian Umer Shafiq ${ }^{1}$ D $\cdot$ Yun Jia Chong ${ }^{1} \cdot$ Hisham Khaled Ben Mahmud $^{1} \cdot$ Md Mofazzal Hossain $^{2} \cdot$ Reza Rezaee $^{2} \cdot$ \\ Nadia Testamanti ${ }^{2}$
}

Received: 22 July 2018 / Accepted: 5 October 2018 / Published online: 11 October 2018

(c) The Author(s) 2018

\begin{abstract}
Emulsified acid has attracted considerable attention of the oil and gas industry due to its delayed nature that allows deeper penetration of acid into the formation which essentially facilitate further enhancing the well productivity, and at the same time minimizes the corrosion issues. However, emulsified acid has only been extensively studied and applied on carbonate formations. Considering more than half of the reservoirs worldwide are sandstone reservoirs, studying the effects of emulsified acid on sandstone under high-temperature conditions would unlock the potential of emulsified acid and help generate more value for the oil and gas industry by improving the well productivity from sandstone reservoirs. To ensure the applicability of the emulsified acid on the real sandstone reservoir, which usually has a temperature higher than ambient conditions, the stability of emulsified acids is investigated under $300^{\circ} \mathrm{F}$. Then, the stable emulsified acid samples are developed and their impact on the properties of Berea sandstone core samples, including porosity, pore-size distribution, permeability and wettability, are investigated. The core samples have undergone pre-flush $\left(10 \% \mathrm{HCl}: 5 \% \mathrm{CH}_{3} \mathrm{COOH}\right)$ before the main flush (emulsified acid). The emulsified acids are prepared using hydrofluoric acid, hydrochloric acid, phosphoric acid, cationic surfactant and chelating agent. Fourteen core samples are saturated with different emulsified acids under vacuum conditions for 3 days to ensure maximum saturation. The porosity, permeability and wettability of each core sample are measured before and after the reaction with acid. Nuclear magnetic resonance analysis has been applied to evaluate the change in pore size distribution. This study has demonstrated that the emulsified acids are capable of improving the porosity and permeability of Berea sandstone core sample. The pore size distribution has also been affected by the application of emulsified acid, where more large pores have been evolved to the core samples due to the reaction of acids with the sandstone which ultimately helps in improving the productivity of hydrocarbons. This indicates less precipitation of the secondary reaction products resulting better enhancement in sandstone flow properties. These results demonstrate the potential of emulsified acid during sandstone acidizing as emulsified acid significantly improved the sandstone properties which can essentially enhance the well productivity.
\end{abstract}

Keywords Emulsified acid $\cdot$ Matrix acidizing $\cdot$ Stability $\cdot$ Permeability $\cdot$ Wettability

\section{Introduction}

Acidizing has been applied in the oil and gas industry to improve the productivity of the producer wells or injectivity of the injectors (Sidaoui and Sultan 2016).

Mian Umer Shafiq

umer.engr@hotmail.com

1 Curtin University Malaysia, CDT 250, 98009 Miri, Sarawak, Malaysia

2 Department of Petroleum Engineering, Curtin University, Perth, WA 6102, Australia
Conventional straight acid has high reactivity and thus it has the ability to dissolve mineral particles efficiently, minimize formation damage around the wellbore, enhance permeability and improve production from the reservoir. However, the shortcoming of conventional acid is that the high reactivity of the plain acid exposes the well tubular to significant corrosion risk besides leading to rapid spending of the acid. Thus, the reaction between the acid and minerals is difficult to be controlled (Sidaoui et al. 2016; Johnson et al. 2016). As a result, acid will be fully spent in the near wellbore region, leaving the deeper formation untreated. In carbonate matrix acidizing, plain acid 
has less efficiency in creating long wormholes. Thus, in an attempt to improve the efficiency of sandstone matrix acidizing, it is suggested that the reaction rate between acid and formation rock should be controlled (Shafiq and Mahmud 2017). Hence, the delayed nature of emulsified acid has attracted the attention of the oil and gas industry as it could decrease the reaction rate, reduce the contact between acid and well tabular and minimise corrosion issues that is related to well integrity, cost and above all issue associated with safety and environment. In carbonate matrix acidizing using emulsified acid, longer conductive flow paths or "wormholes" are induced, thus improving the permeability and productivity of the reservoir (Sabhapondit et al. 2012; Al-Zahrani 2013; Fattah and Nasr-ElDin 2008). Experimental studies and real field application has indicated that emulsified acid can improve carbonate porosity and permeability while minimizing corrosion issues (Sayed et al. 2013; Zakaria et al. 2012; Navarrete et al. 1998; Al-Anazi et al. 1998).

According to Ehrenberg and Nadeau (2005), a significant portion (approximately 50\%) of the hydrocarbon discovered worldwide is trapped in sandstone reservoir. Therefore, the successful application of emulsified acid on carbonate has raised the interest of performing matrix acidizing using emulsified acid in a sandstone reservoir. However, matrix acidizing using emulsified acid is more developed for carbonate and is very rarely studied and applied on sandstone (Navarrete et al. 1998). Hence, emulsified acid is studied in this project to investigate its impact on sandstone properties, including porosity, permeability, topology and wettability.

An emulsified acid consists of two phases, where diesel is the continuous phase and acid is dispersed in the diesel (Fattah and Nasr-El-Din 2008). The diesel behaves as a diffusion barrier between the formation rock and acid (Daccord et al. 1989; Crowe and Miller 1974). Hence, when injected into a formation, acid is slowly released from the diesel as it penetrates into the formation. In carbonation matrix acidizing using emulsified acid, the delayed nature of the emulsified acid allows longer wormholes to be induced while keeping the corrosion rate at minimum rate (Nasr-El-Din et al. 2000; Almutairi et al. 2012; Buijse and van Domelen 2000).

Another advantage of emulsified acid over conventional acid is that when used in a heterogeneous reservoir, emulsified acid can enhance the acid diversion and wellbore coverage across the targeted thickness of the reservoir (Jones and Davies 1998; Jones and Dovle 1996). On the other hand, plain acid has a viscosity similar to water. Hence, it will tend to flow into the formation intervals with higher permeability, leaving the tight zone with high formation damage untreated (Zakaria and Nasr-El-Din 2016). This non-uniform coverage of acid in the reservoir could lead to unsuccessful acidizing. Therefore, the emulsified acid, which has approximately $50 \mathrm{cP}$ viscosity could enhance the zonal coverage, sweep efficiency and acid distribution in a highly heterogeneous reservoir (Buijse and van Domelen 2000).

Emulsions have been proposed in the area of conformance as a flow diverging agent. The key limitation of emulsions in that process is twofold:

- For the conformance treatment to be successful, the emulsion viscosity should be very high. This also means that injectivity will be low, therefore, the process needs to be compromised.

- Even if the emulsion is able to be injected in the reservoir, the effectiveness may not be long lasting due to its thermodynamic instability.

Recently, Torrealba and Hoteit (2018) showed that microemulsions, which are thermodynamically stable, are superior alternatives for conformance.

This study focuses on the potential application of emulsified acids for enhancing production performance from sandstone reservoir by improving the porosity and permeability, and wellbore coverage across the targeted thickness of the reservoir based upon experimental investigation.

\section{Methodology}

The chemicals used in this project are presented in Table 1. These chemicals and acids were mixed at different ratios and allowed to react with sandstone formation. After that different analytical techniques were used to determine the change in core sample properties due to acidizing.

\section{Synthesis method}

First, the volume of distilled water, acid and diesel is calculated using Eq. 1 (Shafiq and Shuker 2013)

$M_{1} V_{1}=M_{2} V_{2}$

where $V_{2}$ is the total volume of the mixture which is set to be $150 \mathrm{ml}$ for this study. $M_{1}$ given saturation of the acid by

Table 1 List of chemicals

\begin{tabular}{ll}
\hline Name of chemical & Purity \\
\hline Hydrofluoric acid (HF) & $40 \%$ \\
Hydrochloric acid $(\mathrm{HCl})$ & $37 \%$ \\
Phosphoric acid $\left(\mathrm{H}_{3} \mathrm{PO}_{4}\right)$ & $85 \%$ \\
Formic acid $(\mathrm{HCOOH})$ & $100 \%$ \\
Acetic acid $\left(\mathrm{CH}_{3} \mathrm{COOH}\right)$ & $100 \%$ \\
Hexadecyltrimethylammonium Bromide (CTAB) & - \\
Hydroxyethyl ethylene-diaminetriacetic acid (HEDTA) & - \\
Diesel & - \\
\hline
\end{tabular}


the supplier (In Liquid form). $M_{2}$ saturation of the acid in the combination. $V_{1}$ volume of the acid to be added in the solution.

After calculating the volume required, then acid and water are mixed together. The cationic surfactant (CTAB) and HEDTA chelating agent were added in the water-acid mixture while stirring at $4000 \mathrm{rpm}$ speed under homogenizer. Using the same method, total of 14 emulsified acid samples were prepared as shown in Table 2.

\section{Stability}

The stability of emulsified acid under high-temperature conditions was tested where the emulsified acid sample was placed in a water bath, which was heated via a hot plate at a temperature of $70{ }^{\circ} \mathrm{C}$. The stability of the emulsified acid was closely monitored by identifying the separation of fluids every hour for $24 \mathrm{~h}$.

\section{Saturation}

The Berea core samples were cut into a desirable size (1.5 in dimeter and 3 in length). Core samples numbered $1-15$ were then saturated with preflush fluid $\left(5 \% \mathrm{HCl}: 10 \% \mathrm{CH}_{3} \mathrm{COOH}\right)$ for 3 days under a temperature of $70{ }^{\circ} \mathrm{C}$. After 3 days, the core samples were cleaned and dried thoroughly. The samples were then saturated with different combinations of emulsified acids for 3 days at $70{ }^{\circ} \mathrm{C}$. This saturation process is performed in the fume hood for safety purposes. Core sample 16 was selected as the reference sample as it was saturated with emulsified acid combination of standard acid.

Table 2 NMR porosity

\begin{tabular}{|c|c|c|c|}
\hline Sample & $\begin{array}{l}\text { Emulsion combi- } \\
\text { nation (vol/vol) }\end{array}$ & Acid combination (vol\%) & NMR $(\%)$ \\
\hline 1 & 0.7 acid:0.3 diesel & $3 \% \mathrm{HF}: 9 \% \mathrm{H}_{3} \mathrm{PO}_{4}$ & 18.02 \\
\hline 2 & 0.7 acid:0.3 diesel & $1.5 \% \mathrm{HF}: 9 \% \mathrm{H}_{3} \mathrm{PO}_{4}$ & 18.36 \\
\hline 3 & 0.7 acid:0.3 diesel & $1.5 \% \mathrm{HF}: 9 \% \mathrm{HCOOH}$ & 19.58 \\
\hline 4 & 0.7 acid:0.3 diesel & $3 \% \mathrm{HF}: 9 \% \mathrm{HCOOH}$ & 19.84 \\
\hline 5 & 0.7 acid:0.3 diesel & $3 \% \mathrm{HF}: 12 \% \mathrm{HCl}$ & 20.15 \\
\hline 6 & 0.7 acid:0.3 diesel & $3 \% \mathrm{HF}: 12 \% \mathrm{H}_{3} \mathrm{PO}_{4}$ & 16.64 \\
\hline 7 & 0.7 acid:0.3 diesel & $3 \% \mathrm{HF}: 12 \% \mathrm{HCOOH}$ & 19.84 \\
\hline 8 & 0.7 acid:0.3 diesel & $3 \% \mathrm{HF}: 9 \% \mathrm{HCl}$ & 21.17 \\
\hline 9 & 0.8 acid:0.2 diesel & $3 \% \mathrm{HF}: 9 \% \mathrm{H}_{3} \mathrm{PO}_{4}$ & 17.90 \\
\hline 10 & 0.8 acid:0.2 diesel & 1.5\%HF:9\%HCOOH & 19.46 \\
\hline 11 & 0.8 acid:0.2 diesel & $3 \% \mathrm{HF}: 12 \% \mathrm{HCl}$ & 20.96 \\
\hline 12 & 0.6 acid:0.4 diesel & $3 \% \mathrm{HF}: 9 \% \mathrm{H}_{3} \mathrm{PO}_{4}$ & 18.43 \\
\hline 13 & 0.6 acid:0.4 diesel & $1.5 \% \mathrm{HF}: 9 \% \mathrm{HCOOH}$ & 19.94 \\
\hline 14 & 0.6 acid:0.4 diesel & $3 \% \mathrm{HF}: 12 \% \mathrm{HCl}$ & 21.09 \\
\hline 15 & & Preflush & 18.99 \\
\hline 16 & & Initial sample & 19.43 \\
\hline
\end{tabular}

\section{Permeability}

The core samples were saturated in distilled water under vacuum condition for 3 days. A suction pressure of $0.05 \mathrm{Mpa}$ and temperature of $25^{\circ} \mathrm{C}$ was applied. Due to the vacuum condition, the gas trapped in the pore space was removed. Consequently, the distilled water filled up the pore spaces efficiently. After saturation, the core samples were then dried in the furnace for $24 \mathrm{~h}$ at a temperature of $70{ }^{\circ} \mathrm{C}$. Then, gas permeameter is used to measure the permeability of the core samples. The initial, pre flushed and emulsified saturated core samples permeability can then be calculated using the data obtained from the experiments and applying Eqs. 2 and 3 . Equation 2 is used to calculate the permeability by obtaining the data from manual permeameter while Eq. 3 is used to calculate the viscosity of the gas used during the permeability measurement using permeameter.

$K_{a}=\frac{2 \mu Q_{b} P_{b} L}{A\left(P_{1}^{2}-P_{2}^{2}\right)} \times 1000$

$\mu=\frac{13.85 \times T^{1.5}}{T+102} \times 0.0001$

where $K_{a}$ Permeability (md), $\mu$ viscosity (cp), $Q_{b}$ flow rate (cc/sec), $P_{b}$ standard pressure (psia), $L$ lenth of core sample (cm), $A$ area of core sample $\left(\mathrm{cm}^{2}\right), P_{1}$ downstream pressure (psia), $P_{2}$ upstream pressure (psia), $T$ temperature (K).

\section{Nuclear magnetic resonance}

The NMR is used to determine the transverse relaxation time (T2) to identify the presence of large pores, estimate pore size distribution and porosity of the core samples. The NMR test has been performed on $2 \mathrm{MHz}$ Magritek Rock Core Analyzer. The plug was initially saturated with $5 \%$ brine water under vacuum condition for $72 \mathrm{~h}$ until the weight remained constant, indicating a fully saturated status for NMR test. Then the samples were heated to $35^{\circ} \mathrm{C}$ and inserted into the NMR chamber to perform the relaxation time (T2) measurement.

\section{Result and discussion}

\section{Stability test}

Emulsified acid samples with $1 \mathrm{wt} \%$, of CTAB, $3 \mathrm{wt} \%$ of $\mathrm{CTAB}$ and $5 \mathrm{wt} \% \mathrm{CTAB}$ were prepared and their stability was tested at a temperature of $70^{\circ} \mathrm{C}$. The results showed that $1 \mathrm{wt} \%$ and $3 \mathrm{wt} \%$ of surfactant was insufficient to produce a stable emulsion as an oil layer was observed after $15 \mathrm{~min}$. This indicates that the phase separation has occurred. The

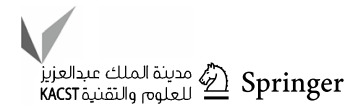


emulsified acid with 5 wt\% CTAB showed significantly greater stability and was able to remain stable for more than $24 \mathrm{~h}$. Hence, all other emulsified acid samples were prepared using $5 \mathrm{wt} \%$ of CTAB as a surfactant to obtain a stable emulsion.

\section{Colour change test}

After saturating core samples number 1-15 with preflush fluid of $5 \% \mathrm{HCl}: 10 \% \mathrm{CH}_{3} \mathrm{COOH}$ for a duration of 3 days, the colour of the core samples changed from grey to yellowish brown as shown in Fig. 1a, b. This could indicate that not only the minerals were dissolved due to the reaction between the acid and the core samples, but also some reaction products could have been formed. These products could potentially be iron(III) $\left(\mathrm{Fe}^{3+}\right)$ or iron(III) tetrachloro complex $\left(\mathrm{FeCl}^{4-}\right)$, which were formed due to the reaction between iron ions and chloride ions which then resulted in the change in colour of the core samples into a yellowish
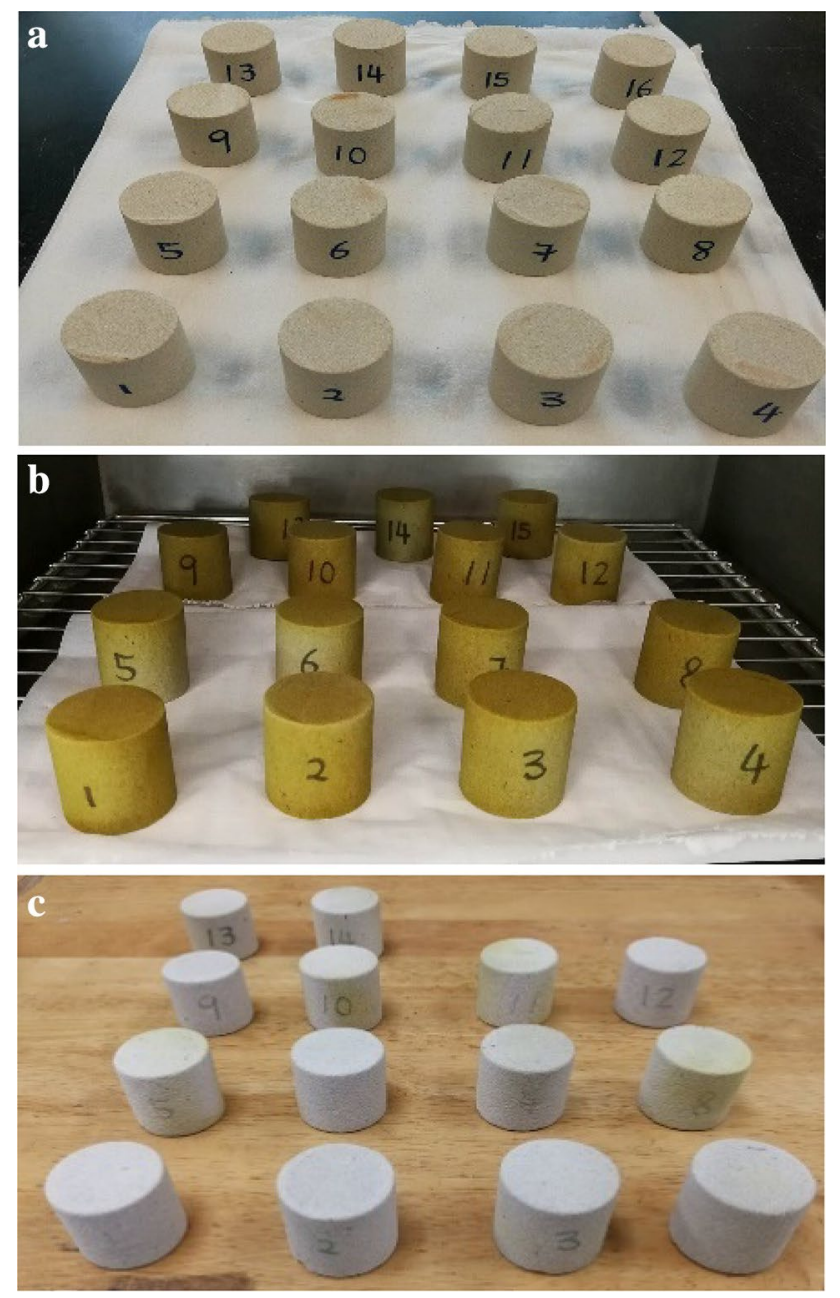

Fig. 1 The colour of the core sample (a) at initial condition, b after saturating with preflush, $\mathbf{c}$ after saturating with emulsified acid brown colour. These colour changes were also observed by Shafiq and Shuker (2013), whereby the colour of the core samples changed to yellowish after saturating with acid.

Core samples 1-14 were then saturated with emulsified acid which consequently caused the samples to change from yellowish grey to pale grey as shown in Fig. 1b, c. In addition to that, the surface of the core samples became rougher and the serial number which was used to identify the core sample has faded. This is a strong evidence that the minerals have gone through reaction and dissolution. The dissolution of the minerals by emulsified acid can also be proved by measuring the change in dry weight of the core samples before and after acid treatment.

\section{NMR analysis}

Using the NMR method, the porosity of the core samples was obtained and the results are shown in Fig. 2. The porosity measured is the effective porosity that may contribute to the production of hydrocarbon.

Figure 2 indicates the effective porosity of the core samples. With reference to sample 16 (initial sample), it is observed that the porosity of some of the samples has been reduced. Sample 6 has suffered the most significant porosity reduction whereby its porosity was determined to be $16.64 \%$, which is $14.38 \%$ less than the initial porosity value of $19.43 \%$. Core samples that were treated with emulsified acid containing $\mathrm{HF}: \mathrm{H}_{3} \mathrm{PO}_{4}$ also caused a porosity reduction as compared to the initial sample. This demonstrates that an emulsified acid containing $\mathrm{HF}: \mathrm{H}_{3} \mathrm{PO}_{4}$ is not efficient in improving the porosity. This may be due to the precipitation of minerals after acidizing. NMR method indicated that the emulsified acid containing $\mathrm{HF}: \mathrm{HCl}$ provides the most significant porosity improvement, followed by $\mathrm{HF}: \mathrm{HCOOH}$ and HF: $\mathrm{H}_{3} \mathrm{PO}_{4}$. The NMR test also provides as estimation of the distribution of pore sizes by measuring the induced magnetic moment of the proton (hydrogen nuclei) of the fluid that occupies the pore spaces of the core sample. The pore size distribution of the core samples is shown in Fig. 3.

From Fig. 3, it is evident that treatment of the core sample with emulsified acid has created more numbers of larger pores when compared to reference sample 16, assuming that the core samples are homogeneous and isotropic. The presence of larger pores is indicated by the higher $T_{2}$ value. The cutoff value is considered to be 10 and hence any value smaller than $10 \mathrm{~ms}$ is considered to represent the bulk volume irreducible (BVI) and any value larger than $10 \mathrm{~ms}$ represents the Free Fluid Index (FFI). Thus, any fluids in the pore spaces that show a relaxation time smaller than $10 \mathrm{~ms}$ is immobile and will not contribute to the production of hydrocarbon. On the other hand, a relaxation time which is greater than 10 indicates large pores that will contribute to the production of hydrocarbon. 
Fig. 2 Cumulative porosity with time for various core samples obtained from NMR studies
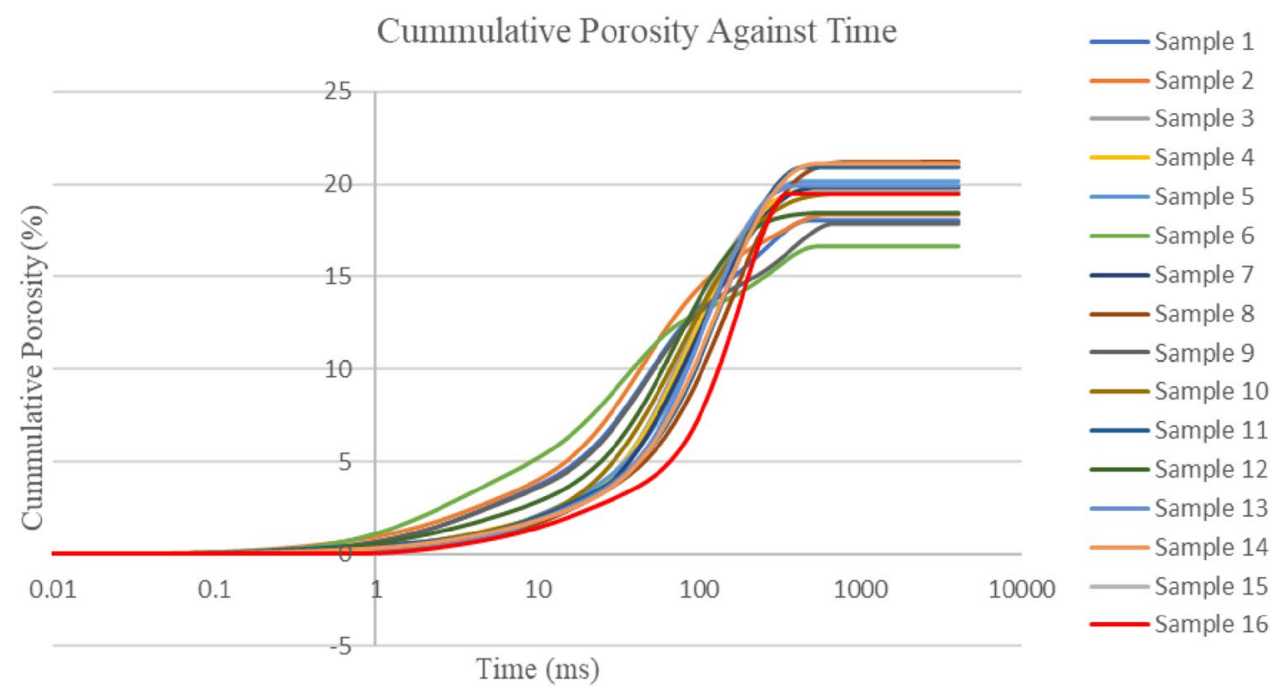

Fig. 3 Incremental porosity of the pore sample with time
Incremental Porosity Against Time

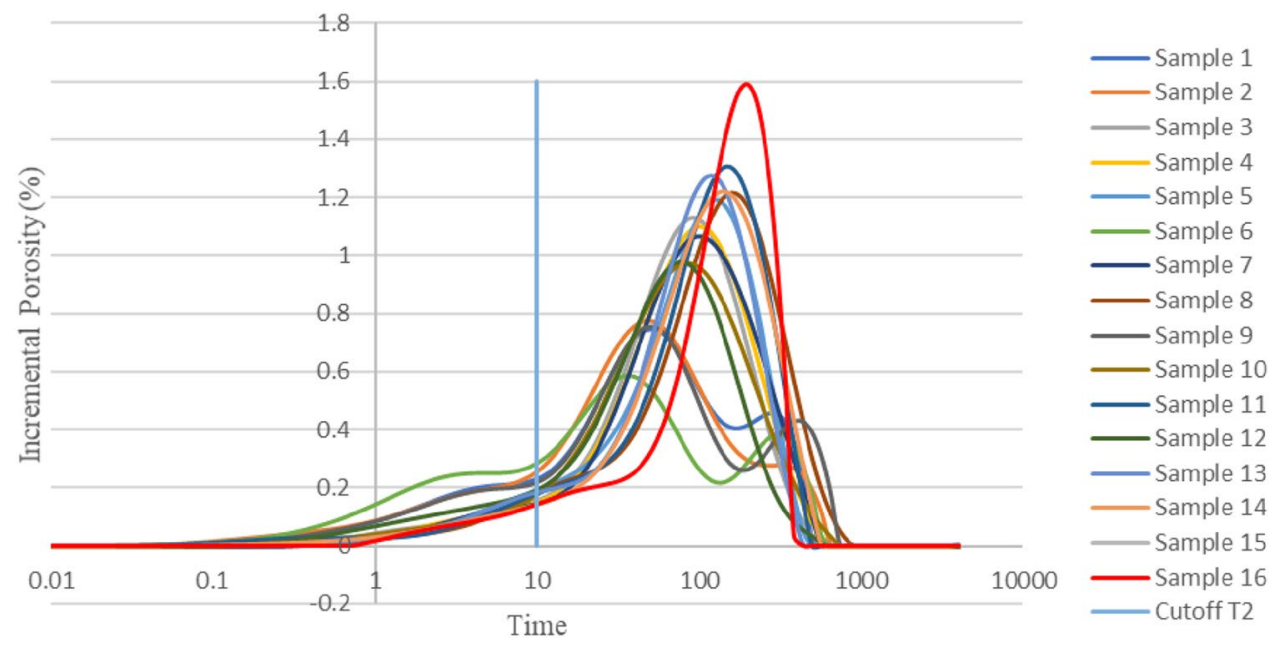

Treatment with emulsified acid has impacted the samples in a way that the pore size distribution has become more heterogeneous. More small and large pores have been created due to the dissolution of minerals. The larger pores have a high potential of increasing the fluid flow ability since the capillary pressure in the pore throats is lower. The increase in the number of small pores after acidizing is a good indicator that the preflush and main flush (emulsified acid) has removed the fine particles and minerals, resulting in new pore spaces. Table 2 represents the porosity value of each sample obtained using NMR logging technique.

\section{Permeability}

The permeability of each core sample was calculated and shown in Fig. 4.

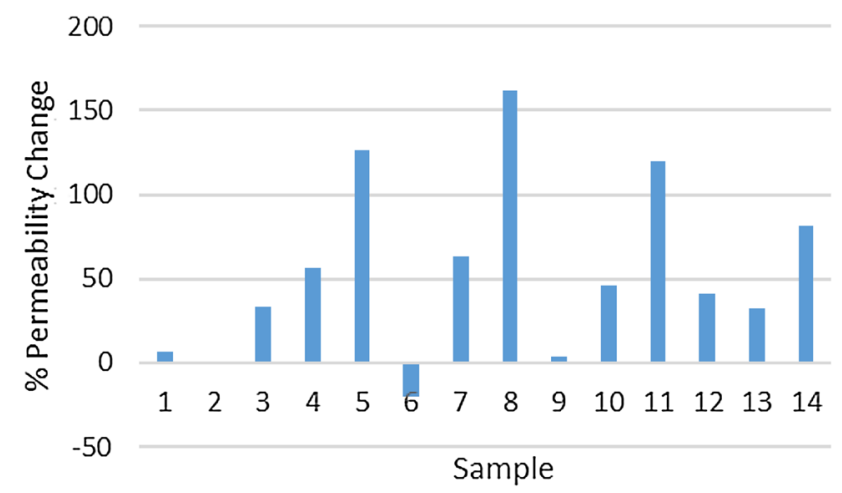

Fig. 4 Permeability change after acidizing 
Based on Table 3 (appendix), it is shown that the emulsified acid containing phosphoric acid is the least effective in enhancing the permeability regardless of the ratio of acid used. Best case scenario, the use of phosphoric acid was able to increase the permeability by a maximum of $41 \%$. However, permeability was also seen to be reduced by $20.1 \%$ in one of the samples.

The permeability increment is most significant when hydrochloric acid was used in the emulsified acid. Permeability improved by $81 \%-162 \%$, which is a very significant and successful permeability enhancement. This result indicates that the conventional and most widely used mud acid still provides the best permeability increment after being emulsified in diesel. There are several concerns and drawbacks of using mud acid such as high corrosion rate and high reactivity of $\mathrm{HF}: \mathrm{HCl}$ combination. However, this can be can be improved by the emulsified acid. The continuous phase of diesel could slow down the reaction rate, thus allowing a deeper penetration of the acid while also minimizing the rate of corrosion.

Formic acid (HCOOH) is also an effective acid to be used in emulsified acid to enhance the permeability of the Berea core sample. The results show that it has successfully increased the permeability by $33-63 \%$. The emulsified acid using 0.7 acid:0.3 diesel with $3 \% \mathrm{HF}: 12 \% \mathrm{HCOOH}$ is the optimum emulsified acid as compared to other emulsified acid with $1.5 \% \mathrm{HF}$ or $9 \% \mathrm{HCOOH}$. The higher concentration of HF allows a better dissolution and removal of the aluminosilicates.

\section{Conclusions}

Emulsified acid is found to have huge potential in improving the production performance of sandstone reservoir by enhancing porosity and permeability. In this particular study, emulsified acid with 7-3 acid-to-oil ratio that contains 3\% $\mathrm{HF}: 9 \% \mathrm{HCl}$ gives the best porosity and permeability enhancement for Berea sandstone.

Generally, the emulsified acid that contains HF: $\mathrm{HCl}$ acids is more efficient in improving the properties of Berea sandstone core sample, including the porosity, permeability and topology. Emulsified acid containing HF:HCOOH, followed by $\mathrm{HF}: \mathrm{H}_{3} \mathrm{PO}_{4}$ is less effective.

To further investigate the impact of emulsified acid on sandstone properties and increase the feasibility of the application of emulsified acid on sandstone reservoir, core flooding is suggested to be performed as matrix acidizing is a dynamic progress where the acid is injected into the reservoir continuously. On top of that, the hydrocarbon recovery factor could be identified directly from the core flooding.
In addition, to ensure the emulsified acid is applicable to other types of sandstone formation with different mineralogy, the test should be carried out on different types of sandstone samples. Other than that, for future studies, it is suggested to conduct the experiments at a temperature of $150^{\circ} \mathrm{C}$ as high-temperature reservoir is defined to have the temperature ranged between 150 and $205^{\circ} \mathrm{C}$ (DeBruijn et al. 2008).

\section{Future studies}

Introduction of CTAB surfactant in emulsified acid can lower the interfacial tension capabilities, which may allow to mobilize trapped oil and allow for improved contact with the reservoir rock (Huh 1979; Torrealba and Johns 2017).

\section{Limitations}

Emulsions are not thermodynamically stable. This makes them challenging fluids to characterize: whatever property we measure in the lab is only a snapshot in time, and may not be representative of the same system as time passes or conditions change.

Open Access This article is distributed under the terms of the Creative Commons Attribution 4.0 International License (http://creativeco mmons.org/licenses/by/4.0/), which permits unrestricted use, distribution, and reproduction in any medium, provided you give appropriate credit to the original author(s) and the source, provide a link to the Creative Commons license, and indicate if changes were made.

Table 3 Change in permeability

\begin{tabular}{llll}
\hline Sample & \multicolumn{3}{l}{ Permeability, Ka $(\mathrm{mD})$} \\
\cline { 2 - 4 } & Initial & Preflush & Emulsified acid \\
\hline 1 & 180.52 & 199.69 & 191.72 \\
2 & 151.32 & 166.78 & 149.47 \\
3 & 200.62 & 227.85 & 267.24 \\
4 & 215.85 & 251.16 & 337.18 \\
5 & 144.49 & 158.04 & 326.79 \\
6 & 202.13 & 236.42 & 161.44 \\
7 & 206.43 & 241.38 & 336.82 \\
8 & 230.16 & 270.81 & 602.19 \\
9 & 198.90 & 227.93 & 205.81 \\
10 & 195.40 & 223.19 & 284.36 \\
11 & 201.95 & 229.63 & 443.18 \\
12 & 141.51 & 154.27 & 199.84 \\
13 & 215.59 & 246.10 & 285.34 \\
14 & 206.78 & 240.87 & 374.73 \\
15 & 143.02 & 158.78 & - \\
16 & 211.72 & - & - \\
\hline
\end{tabular}




\section{Appendix}

See Table 3.

\section{References}

Al-Anazi H, Nasr-El-Din H, Mohamed S (1998) Stimulation of tight carbonate reservoirs using acid-in-diesel emulsions: field application. SPE formation damage control conference. https://doi. org/10.2118/39418-ms

Almutairi S, Al-Obied M, AlYami I, Shebatalhamd A, Al-Shehri D (2012) Wormhole propagation in tar during matrix acidizing of carbonate formations. SPE international symposium and exhibition on formation damage control. https://doi.org/10.2118/15156 0 -ms

Al-Zahrani A (2013) Innovative method to mix corrosion inhibitor in emulsified acids. International petroleum technology conference. https://doi.org/10.2523/iptc-16946-ms

Buijse M, van Domelen M (2000) Novel application of emulsified acids to matrix stimulation of heterogeneous formations. SPE Prod Facil 15(03):208-213. https://doi.org/10.2118/65355-pa

Crowe C, Miller B (1974) New, Low-Viscosity acid-in-oil emulsions provide high degree of retardation at high temperature. SPE rocky mountain regional meeting. https://doi.org/10.2118/4937-ms

Daccord G, Touboul E, Lenormand R (1989) Carbonate acidizing: toward a quantitative model of the wormholing phenomenon. SPE Prod Eng 4(01):63-68. https://doi.org/10.2118/16887-pa

DeBruijn G, Skeates C, Greenaway R, Harrison D, Parris M, James S et al (2008) High-pressure, high-temperature technologies. Oilfield Rev 20(3)

Ehrenberg S, Nadeau P (2005) Sandstone vs. carbonate petroleum reservoirs: a global perspective on porosity-depth and porositypermeability relationships. AAPG Bull 89(4):435-445. https:// doi.org/10.1306/11230404071

Fattah AW, Nasr-El-Din H (2008) Acid emulsified in xylene: a costeffective treatment to remove asphalting deposition and enhance well productivity. SPE eastern regional/AAPG eastern section joint meeting. https://doi.org/10.2118/117251-ms

Huh C (1979) Interfacial tensions and solubilizing ability of a microemulsion phase that coexists with oil and brine. J Colloid Interface Sci 71(2):408-426

Johnson L, Shepherd S, Rothrock G, Cairns A, Al-Muntasheri G (2016) Core/shell systems for delayed delivery of concentrated mineral acid. SPE Prod Oper 31(04):351-361. https://doi. org/10.2118/173734-pa

Jones A, Davies D (1998) Quantifying acid placement: the key to understanding damage removal in horizontal wells. SPE Prod Facil 13(03):163-169. https://doi.org/10.2118/50975-pa

Jones A, Dovle M (1996) Improving the efficiency of matrix acidizing with a succinoglycan viscosifier. SPE Prod Facil 11(03):144-149. https://doi.org/10.2118/30122-pa
Nasr-El-Din H, Al-Anazi H, Mohamed S (2000) Stimulation of waterdisposal wells using acid-in-diesel emulsions: case histories. SPE Prod Facil 15(03):176-182. https://doi.org/10.2118/65069-pa

Navarrete R, Holms B, McConnell S, Linton D (1998) Emulsified acid enhances well production in high-temperature carbonate formations. European petroleum conference. https://doi. org/10.2118/50612-ms

Sabhapondit A, Vielma J, Prakash C (2012) Laboratory optimization of an emulsified acid blend for stimulation of high-temperature carbonate reservoirs. North Africa technical conference and exhibition. https://doi.org/10.2118/150337-ms

Sayed M, Nasr-El-Din H, Nasrabadi H (2013) Reaction of emulsified acids with dolomite. J Can Petrol Technol 52(03):164-175. https ://doi.org/10.2118/151815-pa

Shafiq MU, Mahmud HB (2017) Sandstone matrix acidizing knowledge and future development. J Petrol Explor Prod Technol 7:1205. https://doi.org/10.1007/s13202-017-0314-6

Shafiq M, Shuker M (2013) Finding suitable acid for acidizing of low permeable sandstone formation: a research. SPE/PAPG annual technical conference. https://doi.org/10.2118/169641-ms

Sidaoui Z, Sultan A (2016) Formulating a stable emulsified acid at high temperatures: stability and rheology study. International petroleum technology conference. https://doi.org/10.2523/iptc19012-ms

Sidaoui Z, Sultan A, Qiu X (2016) Viscoelastic properties of novel emulsified acid using waste oil: effect of emulsifier concentration, mixing speed and temperature. SPE Kingdom Of Saudi Arabia annual technical symposium and exhibition. https://doi. org/10.2118/182845-ms

Torrealba VA, Hoteit H (2018) Conformance improvement in oil reservoirs by use of microemulsions. Presented in the SPE Kingdom of Saudi Arabia annual technical symposium and exhibition, 23-26 April, Dammam, Saudi Arabia. https://doi.org/10.2118/19228 9-MS

Torrealba VA, Johns RT (2017) Coupled interfacial tension and phase behavior model based on micellar curvatures. Langmuir 33(47):13604-13614

Zakaria A, Nasr-El-Din H (2016) A novel polymer-assisted emulsifiedacid system improves the efficiency of carbonate matrix acidizing. SPE J 21(03):1061-1074. https://doi.org/10.2118/173711-pa

Zakaria A, Sayed M, Nasr-El-Din H (2012) Propagation of emulsified acids in vuggy dolomitic rocks. SPE Kuwait international petroleum conference and exhibition. https://doi.org/10.2118/16328 8 -ms

Publisher's Note Springer Nature remains neutral with regard to jurisdictional claims in published maps and institutional affiliations. 